\title{
Medical schools to boost numbers of Indigenous students, faculty
}

\author{
C Cite as: CMAJ 2019 June 3;191:E621. doi: 10.1503/cmaj.109-5753
}

Posted on cmajnews.com on May 15, 2019.

anada's 17 medical schools will ensure a minimum number of Indigenous students are admitted each year as part of a new joint commitment to action on Indigenous health.

The medical schools will also develop meaningful relationships with Indigenous communities, build a critical mass of Indigenous faculty, tackle racism in medical education, and implement Indigenous health curricula with a focus on antiracism and anti-colonialism. Moreover, when considering students for admission, schools will assess all candidates' knowledge of Indigenous studies, cultural safety, anti-racism or related disciplines.

To date, action by medical schools to reduce Indigenous health disparities has been "highly variable," says Dr. Marcia Anderson, chair of the Association of Faculties of Medicine of Canada's Indigenous Health Network. "Each of the 17 medical schools is at a different point on their journey."

Most medical schools have a facilitated admissions process for Indigenous students, but as of 2017 , only seven had a set number of seats allocated, and several didn't have courses on Indigenous health issues. Schools have reported a rise in the number of Indigenous students admitted in the past decade, mostly from Métis communities, says Anderson. However, "we haven't seen the same rise in First Nations and Inuit learners."

Numbers of Indigenous faculty also vary. Some schools have none or just one, and others may have "five to ten, depending on if you're talking about someone with paid academic time to participate in governance and policy, or if you're talking

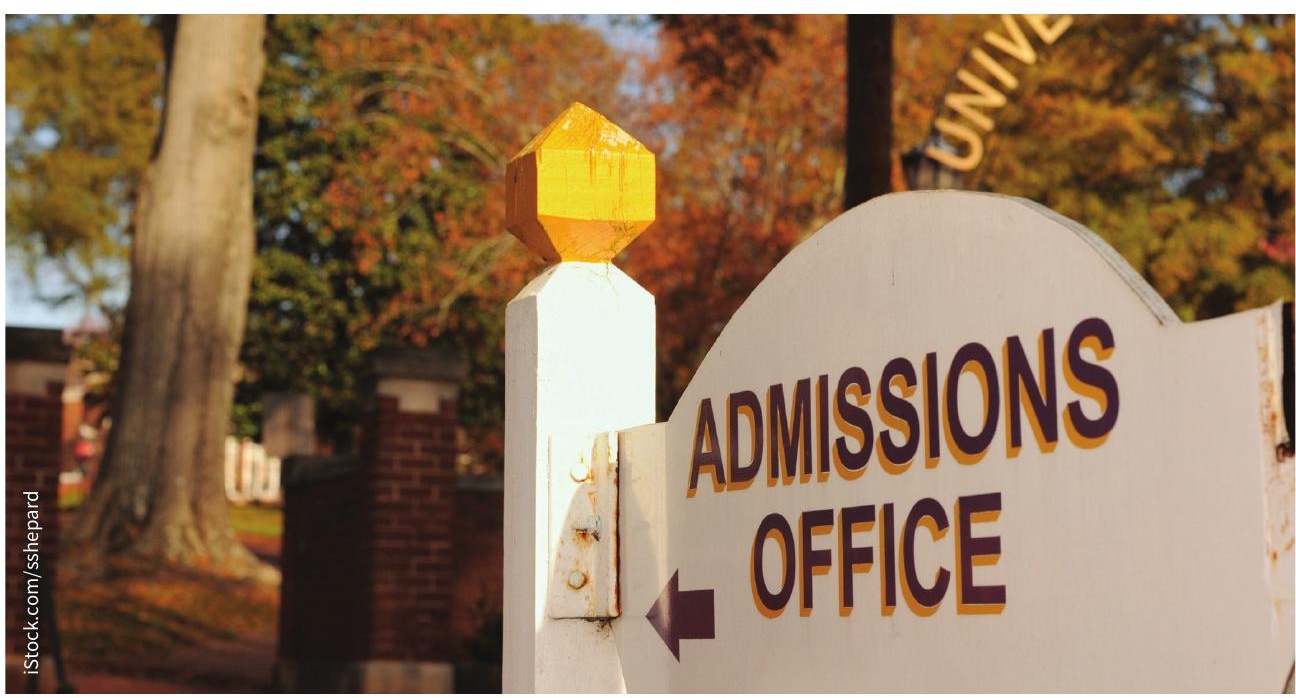

Canadian faculties of medicine are committing to action on Indigenous health, including addressing racial bias in medical education and admissions.

about physicians in the community who may be supervising medical students."

Meanwhile, racism remains a major problem in medical education. Research shows admission assessment tools "all have varying levels of racial bias," Anderson says. And Indigenous students who clear these hoops "still face this idea that they got in the easy way, or they only got in because they're Indigenous."

The new joint commitment is a step forward to "repair the damage done by unequal opportunity in the past," Anderson says. "I'm very hopeful it will start to make structural impacts in the medical schools and contribute to a broader cultural shift."

Boosting the number of Indigenous physicians will be key to improving access to health care for Indigenous people, many of whom live in underserved communities, she notes. Indigenous people have repeat- edly expressed that they "would prefer to see Indigenous physicians."

Some medical educators still resist the idea of setting aside seats for Indigenous students because they believe the current admissions system is objective, Anderson says. "But what's not taken into account by people who believe this is a meritocracy is how unequal opportunity from birth shifts performance," she explains. "If your MCAT score can be predicted based on your postal code or race, then clearly there's something beyond just individual intelligence."

Others take issue with facilitated admissions processes because they believe it gives Indigenous students an unfair advantage. But according to Anderson, "it's just trying to lessen the amount of disadvantage."

Lauren Vogel, CMAJ 